\title{
Prophylactic anticoagulation to prevent venous thromboembolism in traumatic intracranial hemorrhage: a decision analysis
}

\author{
Damon C Scales*1,2,3, Jay Riva-Cambrin4,5, Dave Wells'1, Valerie Athaide6, John T Granton 1,7 and Allan S Detsky8,9
}

\begin{abstract}
Introduction: Patients with intracranial hemorrhage due to traumatic brain injury are at high risk of developing venous thromboembolism including deep vein thrombosis (DVT) and pulmonary embolism (PE). Thus, there is a tradeoff between the risks of progression of intracranial hemorrhage $(\mathrm{ICH})$ versus reduction of DVT/PE with the use of prophylactic anticoagulation. Using decision analysis modeling techniques, we developed a model for examining this trade-off for trauma patients with documented ICH.
\end{abstract}

Methods: The decision node involved the choice to administer or to withhold low molecular weight heparin (LMWH) anticoagulation prophylaxis at 24 hours. Advantages of withholding therapy were decreased risk of ICH progression (death, disabling neurologic deficit, non-disabling neurologic deficit), and decreased risk of systemic bleeding complications (death, massive bleed). The associated disadvantage was greater risk of developing DVT/PE or death. Probabilities for each outcome were derived from natural history studies and randomized controlled trials when available. Utilities were obtained from accepted databases and previous studies.

Results: The expected value associated with withholding anticoagulation prophylaxis was similar (0.90) to that associated with the LMWH strategy (0.89). Only two threshold values were encountered in one-way sensitivity analyses. If the effectiveness of LMWH at preventing DVT exceeded 80\% (range from literature 33\% to 82\%) our model favoured this therapy. Similarly, our model favoured use of LMWH if this therapy increased the risk of ICH progression by no more than $5 \%$ above the baseline risk.

Conclusions: Our model showed no clear advantage to providing or withholding anticoagulant prophylaxis for DVT/ PE prevention at 24 hours after traumatic brain injury associated with $\mathrm{ICH}$. Therefore randomized controlled trials are justifiable and needed to guide clinicians.

\section{Introduction}

It is estimated that more than 1.5 million people in the United States sustain traumatic head injury each year [1]. Radiologic evidence of intracranial hemorrhage at the time of presentation is present in up to $45 \%$ of cases and is associated with a markedly poorer prognosis $[2,3]$. Traumatic intracranial hemorrhage encompasses cerebral contusion, subdural hematoma, subarachnoid hemorrhage, epidural hematoma and intracerebral hemorrhage. These are characterized by a relatively high risk of bleed-

* Correspondence: damon.scales@utoronto.ca

1 Department of Critical Care Medicine, Sunnybrook Health Sciences Centre, 2075 Bayview Avenue, Room D108, Toronto, ON M4N 3M5, Canada

Full list of author information is available at the end of the article ing progression, especially within the first 24 hours $[2,4-$ $6]$.

Traumatic intracranial hemorrhage is also associated with a high risk of thromboembolic complications [7]. This risk is related to the immobility of head-injured patients arising from the underlying neurologic lesion itself, concomitant injuries following trauma, or the use of sedatives and neuromuscular blocking agents. The reported incidence of deep vein thrombosis (DVT) ranges between 18 and $58 \%$ in the absence of anticoagulant prophylaxis [8-11]. DVT is associated with increased morbidity and mortality, including risk of fatal pulmonary embolism (PE) [12]. 
Anticoagulant prophylaxis to prevent DVT is recommended for trauma patients without intracranial or other serious hemorrhage [13]. This therapy is also effective in post-operative neurosurgical patients undergoing brain tumour excision [12]. Only one small quasi-randomized clinical trial has studied anticoagulant prophylaxis versus pneumatic compression devices in patients with intracranial hemorrhage following trauma. This trial found no benefit or harm associated with use of anticoagulant prophylaxis, but only had sufficient sample size to detect very large differences in rates of venous thromboembolism or intracranial hemorrhagic progression [14]. One observational study reported rates of hemorrhagic progression in 150 patients with intracranial hemorrhage that were treated with low molecular weight heparin prophylaxis 24 hours after the initial head injury [15]. One quarter already had radiological evidence of intracranial hemorrhagic progression at the time anticoagulant prophylaxis was started, but only six patients $(4 \%)$ subsequently developed progression in the 24 hours following initiation of anticoagulation prophylaxis. The study lacked a control group limiting inferences regarding the safety and efficacy of this therapy.

Many physicians report routinely withholding anticoagulation prophylaxis in patients with traumatic intracranial hemorrhage because of concerns that it may increase the risk of potentially devastating intracranial hemorrhagic progression [16,17]. Observational studies have also documented variable practice patterns for anticoagulation prophylaxis in such patients. A small retrospective study of 88 patients with traumatic brain injury observed that only $42 \%$ ever received low-molecular weight heparin prophylaxis, and the mean time to initiation of therapy was 14 days [18]. Similarly, a multicentre retrospective study of trauma patients with ICU length of stay greater than seven days found that prophylaxis was initiated within two days in only $25 \%$ of patients, and another quarter did not receive prophylaxis until at least one week following injury [19]. Thus, the use and timing of anticoagulation prophylaxis in these patients remains uncertain and controversial, and most are treated with more conservative and less effective measures such as graduated compression stockings, intermittent pneumatic compression devices, and physiotherapy $[13,16]$.

The lack of persuasive evidence to guide decisions about using anticoagulant prophylaxis in patients with traumatic intracranial hemorrhage implies that clinicians must make decisions based on their own assessments of the risks and benefits. Our objective was to explore the decision to use or withhold anticoagulant prophylaxis in a common clinical scenario characterized by competing risks of hemorrhagic versus thromboembolic complications. We used decision analysis modeling techniques to compare the risks of progression of intracranial hemor- rhage following trauma versus the potential benefits of reducing venous thromboembolism with anticoagulant prophylaxis. Decision analysis involves identifying the most important available clinical choices and determining probabilities of all important potential outcomes following each of these choices [20]. This methodology has been used previously to evaluate the risks and benefits of anticoagulant prophylaxis in neurosurgical patients undergoing craniotomy [21], but to our knowledge has not specifically been used to evaluate patients with traumatic intracranial hemorrhage.

\section{Materials and methods \\ Probabilities and utilities}

We searched Medline (OVID Technologies, New York, NY, USA; 1950 to March 2008) for studies concerning intracranial hemorrhage and anticoagulant thromboprophylaxis using the search terms brain injury, acute; craniocerebral trauma; cerebral hemorrhage, traumatic, anticoagulation, and heparin. We used natural history studies and controlled clinical trials performed in both post-operative neurosurgical and trauma patients to estimate the incidence of DVT [9-12,22]. We estimated the risk of hemorrhagic progression using natural history studies that reported the absolute risk at 24 hours following the neurological injury [15]. The risk of systemic bleeding complications was estimated from rates of major gastrointestinal hemorrhage in critically-ill patients [23]. We used clinical trials of anticoagulation prophylaxis in elective neurosurgical patients to estimate the effectiveness of anticoagulant prophylaxis in preventing DVT and its potential impact on subsequent intracranial bleeding $[12,24,25]$.

Table 1 summarizes the probabilities used in the decision analysis. We obtained utility values (Table 2) from previous publications and the Cost-Effectiveness Analysis Registry from the Institute for Clinical Research and Health Policy Studies, Tufts Medical Center [26-35]. We considered the baseline utility for our study $(0.96)$ to be less than a perfect state of health (1.00) because all patients in our model would have already suffered a major trauma with associated head injury [36]. We subtracted utilities associated with temporary states in our model, such as deep vein thrombosis, from the baseline utility, but we considered events having long-term morbidity, such as disabling neurological deficit, by multiplying the associated utility by the baseline utility [28]. The most severe event that could be encountered in the model was death (utility $=0$ ), and the worst outcome that could be experienced while alive was a severe disabling neurological deficit after progression of intracranial hemorrhage.

We also performed sensitivity analyses considering estimates of benefits and risks of anticoagulant prophy- 
Table 1: Probabilities used in the decision analysis

\begin{tabular}{|c|c|c|c|c|}
\hline Variables & Baseline probability & $\begin{array}{l}\text { Range of plausible } \\
\text { probabilities }\end{array}$ & $\begin{array}{l}\text { Threshold value within } \\
\text { published range }\end{array}$ & Threshold from 0 to 1 \\
\hline Probability of DVT & $0.32[12]$ & 0.18 to $0.50[[9]$ to $[11,12]]$ & No & Yes $\left(>0.6^{*}\right)$ \\
\hline $\begin{array}{l}\text { Probability of PE following } \\
\text { development of DVT }\end{array}$ & $0.1[42,43]$ & 0.01 to $0.18[22,24,44,45]$ & No & Yes $\left(>0.3^{*}\right)$ \\
\hline Probability of death from PE & $0.17[46]$ & 0 to $0.50[47]$ & No & No \\
\hline $\begin{array}{l}\text { Probability of a CNS bleed on } \\
\text { LMWH }\end{array}$ & $0.108[15]$ & 0.03 to $0.23[24,44]$ & No & Yes $\left(>0.017^{+}\right)$ \\
\hline $\begin{array}{l}\text { Effectiveness of LMWH in } \\
\text { preventing DVT (e) }\end{array}$ & $0.47[12]$ & 0.33 to $0.82[12,42]$ & Yes $\left(>0.8^{*}\right)$ & Yes $\left(>0.8^{*}\right)$ \\
\hline $\begin{array}{l}\text { Probability of death from a } \\
\text { CNS bleed }\end{array}$ & $0.105[48]$ & 0.08 to $0.3[49,50]$ & No & No \\
\hline $\begin{array}{l}\text { Probability of disabling } \\
\text { neurological deficit after CNS } \\
\text { bleed }\end{array}$ & $0.17[51]$ & 0.16 to $0.33[52,53]$ & No & No \\
\hline $\begin{array}{l}\text { Probability of an ICU-related } \\
\text { systemic bleed }\end{array}$ & $0.035[23]$ & 0.027 to $0.046[23]$ & No & No \\
\hline $\begin{array}{l}\text { Probability of death from } \\
\text { ICU-related systemic bleed }\end{array}$ & $0.02[23]$ & 0.001 to $0.035[23,46]$ & No & No \\
\hline $\begin{array}{l}\text { Effectiveness of not receiving } \\
\text { LMWH in reducing CNS } \\
\text { bleeds }\end{array}$ & $0.315[4,15]$ & $0.001-0.99[4-6,23,47,54]$ & Yes $\left(>0.05^{+}\right)$ & Yes $\left(>0.05^{+}\right)$ \\
\hline $\begin{array}{l}\text { Effectiveness of not receiving } \\
\text { LMWH in reducing ICU- } \\
\text { related systemic bleeds }\end{array}$ & 0.146 & 0 to $0.66[8,12,55]$ & No & No \\
\hline
\end{tabular}

\section{Table 2: Utilities used in the decision analysis}

\begin{tabular}{|c|c|c|c|c|}
\hline Utility & Baseline value & Published ranges & $\begin{array}{l}\text { Threshold value } \\
\text { within published } \\
\text { range }\end{array}$ & $\begin{array}{l}\text { Threshold value } \\
\text { reached between } \\
0 \text { and } 1\end{array}$ \\
\hline Baseline & $0.96[36]$ & 0.95 to $1.0^{*}$ & No & No \\
\hline LMWH prophylaxis & $0.99[27]$ & 0.9 to $1.0^{*}$ & No & No \\
\hline Living with DVT & $0.95[27]$ & 0.92 to $1.0^{*}$ & No & Yes $\left(>0.9^{+}\right)$ \\
\hline Living with PE & $0.7[35]$ & 0.6 to $0.9[32]$ & No & No \\
\hline Living with massive systemic bleed & $0.7[27]$ & 0.6 to $0.8^{*}$ & No & No \\
\hline Living with a non-disabling ICH & $0.75[33,34]$ & 0.6 to $0.8[33,34,56,57]$ & No & No \\
\hline Living with a disabling $\mathrm{ICH}$ & $0.39[33,34]$ & 0.14 to $0.43[33,34,57]$ & No & No \\
\hline
\end{tabular}

Table of utilities and plausible ranges used for the decision analysis. Ranges with an asterisk $\left(^{*}\right)$ were generated from a consensus of authors. The last two columns indicate variables for which a threshold value was identified in one-way sensitivity analysis. Values with a plus (+) indicate a threshold value above which withholding anticoagulant prophylaxis becomes the preferred strategy. DVT: deep vein thrombosis; ICH: intracranial hemorrhage; LMWH: low molecular weight heparin; PE: pulmonary embolism 
laxis reported on our recent survey of Canadian neurosurgeons and neuro-intensivists [17]. We chose the three most frequent estimates of risk-category selected by survey respondents for risk of intracranial hemorrhagic progression and for risk of DVT/PE with and without anticoagulant prophylaxis. We considered the upper and lower boundaries defined by these three response categories to be the range of plausible values, and chose the median from the most frequent response risk-category to be the point estimate for sensitivity analyses.

\section{Decision node}

The base case for our model was an adult trauma patient ( $\geq 18$ years of age) with intracranial hemorrhage. The single decision node was whether or not to treat with LMWH anticoagulant prophylaxis at 24 hours after head injury and continued until hospital discharge. We assumed that all patients were treated with graduated compression stockings, but we did not consider sequential compression devices because our recent survey of Canadian practice showed these are seldom used in this patient population [17].

We considered the main advantage of anticoagulation prophylaxis to be a reduction in the risk of major thromboembolic complications, including DVT, pulmonary embolism, and death. We considered the disadvantages to be an increased risk of intracranial hemorrhagic progression, other bleeding complications, and the pain of subcutaneous injections. A disabling neurological deficit was defined as being equivalent to a stroke with a Modified Rankin Score $\geq 3$, and a non-disabling neurological deficit was defined as being equivalent to a stroke with a Modified Rankin Score $\leq 2$ [37]. We considered the risks of developing major outcomes during the first thirty days of hospital admission.

\section{Tree structure}

We used TreeAge Pro 2008 (TreeAge Software Inc., Williamstown, MA, USA) to perform the decision analysis. The subtrees in our model are shown in Figures 1, 2 and 3 . We created a linkage term to represent the effectiveness of anticoagulant prophylaxis at reducing the risk of DVT, calculated as follows: effectiveness of anticoagulant prophylaxis $=(($ probability of DVT without LMWH $)-$ (probability of DVT with LMWH))/(probability of DVT without LMWH) (Figure 1) [38]. We used the complement of this effectiveness term (1-effectiveness) in the anticoagulant prophylaxis subtree to ensure that no probabilities would ever have values greater than 1.0, and to guarantee that the risk of DVT would always be highest in patients not receiving anticoagulation. Similarly, we used two linkage terms within the $D V T$ subtree (Figure 2) and the No DVT subtree (Figure 3) to reflect effectiveness of withholding anticoagulant prophylaxis to reduce the risk of systemic bleeding complications or of intracranial bleeding complications. Symmetry was maintained at all major branches of our model and trade-offs at each node were identical for both strategies [38]. The expected utility for each branch was determined by multiplying all of the probabilities along the branches to obtain the probability of being in each state of the terminal nodes. These products of probabilities were then used as the weights to derive the expected value by multiplying the product of probabilities by each of the utilities and then summing these over all outcomes for each branch [39]. Sensitivity analyses were performed across all plausible values for all variables.

\section{Results}

The expected value associated with withholding anticoagulation prophylaxis $(0.90)$ was similar to that associated with the LMWH strategy (0.89; Figure 4). A threshold value was reached within our range of estimates for the effectiveness of anticoagulant prophylaxis for preventing DVT (threshold 0.80, range of estimates 0.33 to 0.82; Figure 5), suggesting that providing $\mathrm{LMWH}$ would have a greater expected value than withholding LMWH only if its effectiveness for preventing DVT exceeded $80 \%$. Similarly, the variable representing the effectiveness of withholding anticoagulant prophylaxis for reducing the risk of intracranial hemorrhagic progression also reached a threshold value within our range of estimates (threshold 0.05 , range of estimates 0.001 to 0.990 ; Figure 6), suggesting LMWH would become the preferred strategy if it increased the risk of $\mathrm{ICH}$ progression by no more than $5 \%$ above the baseline risk.

We performed sensitivity analyses using the most frequently reported risk estimates obtained from our survey of Canadian neurosurgeons and neurointensivists. These analyses did not produce any additional threshold variables and the results did not qualitatively change our findings. We also considered sequential compression devices as a third strategy for preventing DVT. For this analysis, we considered the effectiveness of sequential compression devices for preventing DVT to be between that of LMWH and no anticoagulation prophylaxis (effectiveness 0.19, equivalent to point estimate of DVT incidence of $26 \%$ ) and the risk of intracranial hemorrhagic progression to be the same as no anticoagulation prophylaxis. The expected value of the sequential compression device strategy was 0.90 , similar to that of the other strategies (results not shown, but available upon request).

\section{Discussion}

Our results suggest that the decision of whether or not to use anticoagulant thromboprophylaxis 24 hours after traumatic intracranial hemorrhage is a toss-up. Although 


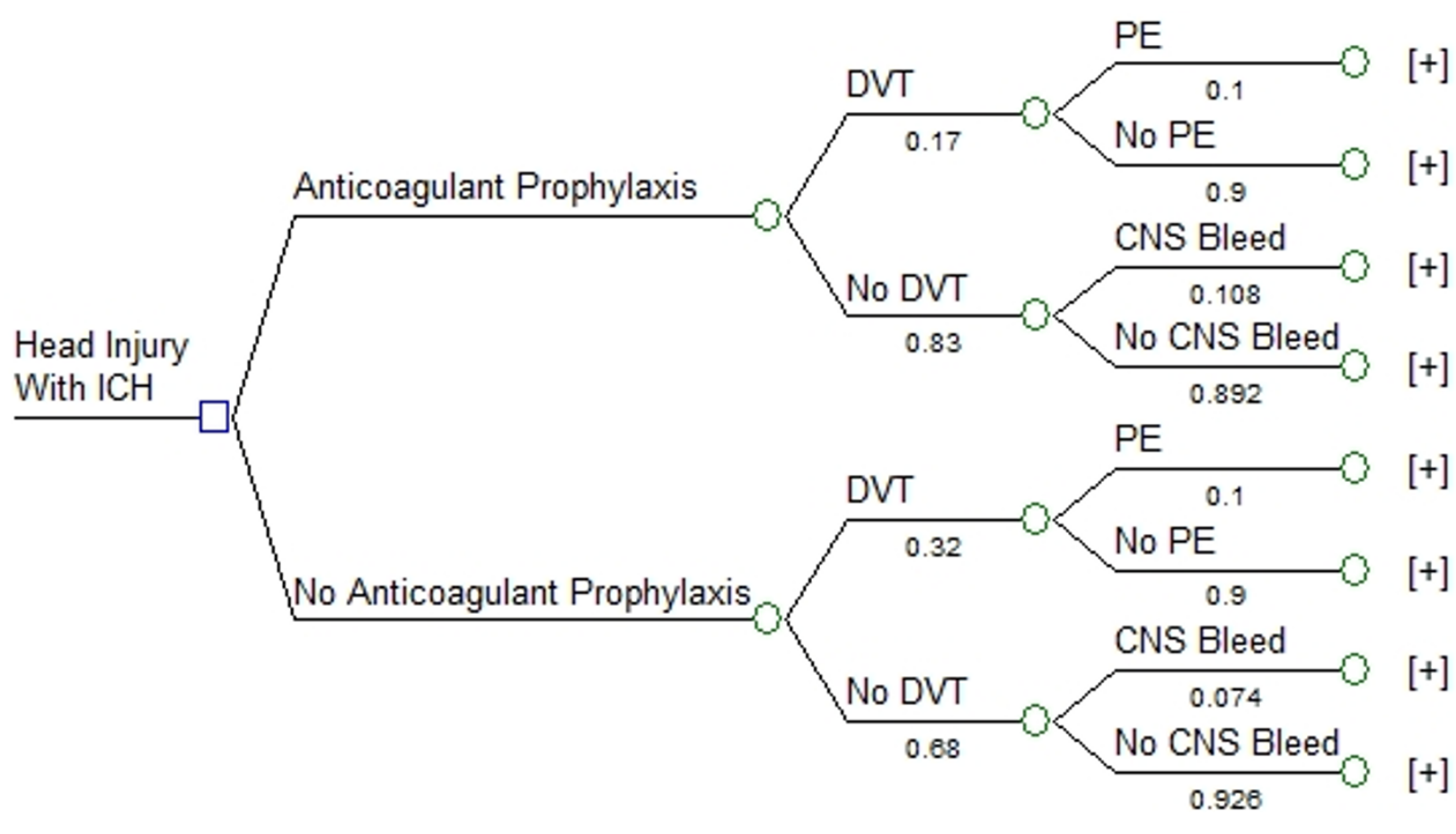

Figure 1 Decision node and anticoagulation subtree. Decision analysis tree demonstrating two strategies: providing anticoagulant prophylaxis at 24 hours to an adult patient following head injury with intracranial hemorrhage $(\mathrm{ICH})$, or withholding anticoagulant prophylaxis. A linkage term representing the complement of the effectiveness of anticoagulant prophylaxis for reducing the risk of DVT was used to link the main subtrees. This effectiveness term was calculated as follows: effectiveness of anticoagulant prophylaxis = $($ (probability of DVT without LMWH) $-($ probability of DVT with LMWH))/(probability of DVT without LMWH). The square node at the extreme left represents the decision node, the circles represent chance nodes, and the plus signs at the far right indicate the presence of additional branches. Numerical values under each branch are the baseline probabilities used at each chance node. CNS Bleed: progression of intracranial hemorrhage; DVT: deep vein thrombosis; PE: pulmonary embolism.

the no prophylaxis strategy was associated with a slightly higher expected value ( 0.90 versus 0.89$)$, this difference is unlikely to be clinically important. For example, the magnitude of this difference is equivalent to the disutility associated with administering a subcutaneous injection of anticoagulant prophylaxis.

Despite the similar expected values associated with each strategy, anticoagulant thromboprophylaxis became the preferred approach only in situations where the incremental risk of hemorrhagic progression was very low, or when its effectiveness in preventing venous thromboembolism was very high. These situations reflect the limits of our plausible risk estimates, and therefore seem unlikely to apply to most clinical situations. Considering the uncertainty, routinely withholding anticoagulant prophylaxis seems an appropriate strategy based on our findings, especially in the early phase when risk of hemorrhagic progression is perceived to be highest [17].

Our results are consistent with the findings of our recent survey of Canadian practice [17]. Of the 160 intensivists and neurosurgeons surveyed, almost two-thirds $(60 \%)$ of intensivists and neurosurgeons indicated they would use, at some time, anticoagulant thromboprophylaxis in patients with intracranial hemorrhage due to traumatic brain injury. However, only one-third (34\%) of these respondents reported that they would start this thromboprophylaxis within two days of the surgery, reflecting their concerns about risk of hemorrhagic progression. However, slightly more than half $(57 \%)$ would start anticoagulation within four days and most (80\%) by one week, suggesting that the perceived risk of hemorrhagic progression decreases over time. We lacked sufficient data to evaluate the risks and benefits of initiating anticoagulant prophylaxis after more than 24 hours, but this could be the topic of future research. We only considered anticoagulant prophylaxis with LMWH rather than unfractionated heparin, reasoning that most available studies in neurosurgical patients used the former and that direct comparisons of these two types of prophylaxis have yielded similar results [40].

Instead of considering anticoagulant prophylaxis, some clinicians may choose to routinely screen patients with ultrasound or other imaging modalities to identify patients with DVT who require treatment with vena cava filters or full-dose anticoagulation, but we did not consider this to be a strategy for DVT prophylaxis. Similarly, depending on available resources some clinicians may choose to use sequential compression devices to prevent 


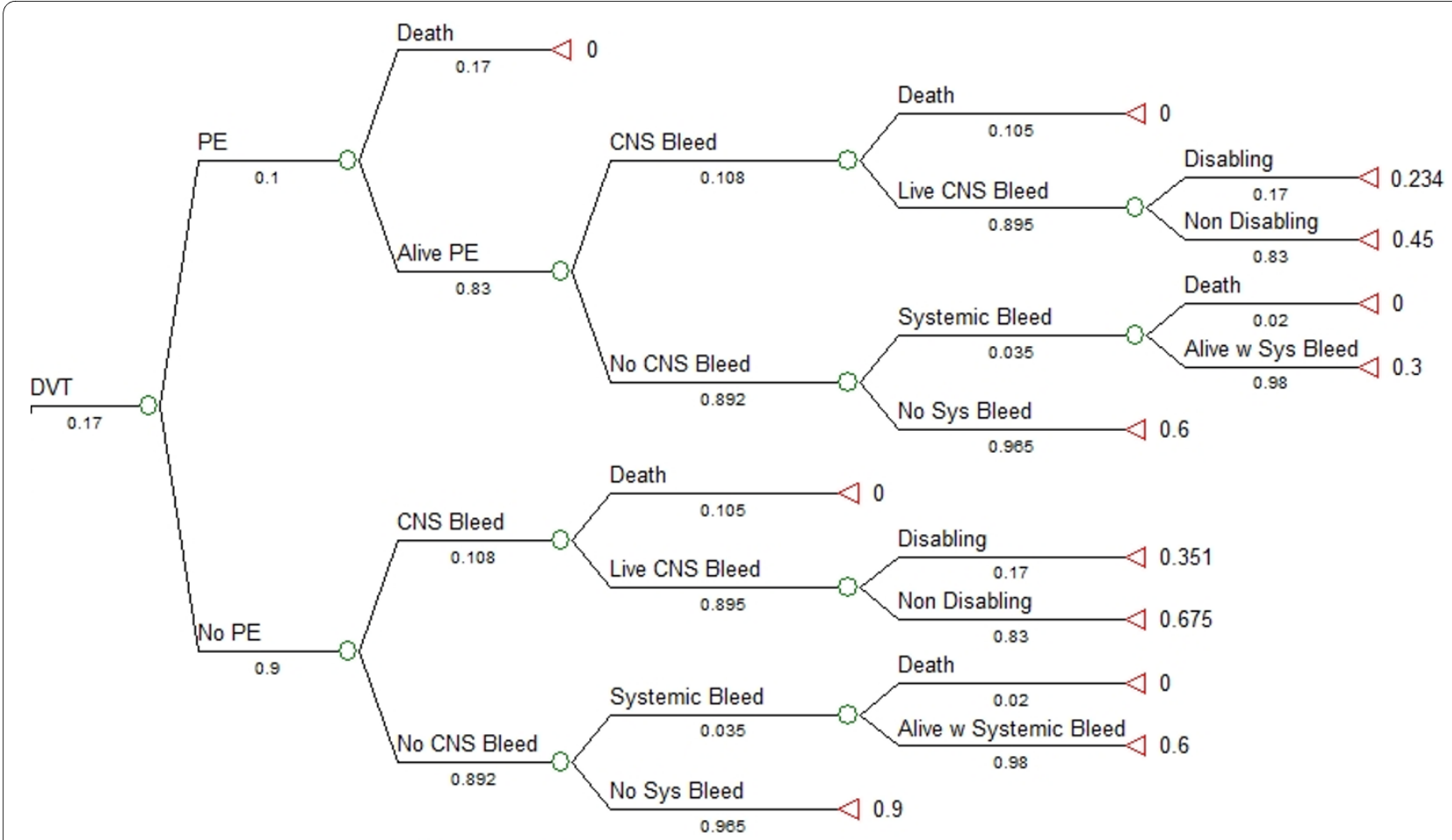

Figure 2 Deep vein thrombosis subtree with systemic bleeding subtrees. Deep vein thrombosis (DVT) subtree showing possible outcomes following development of DVT (tree shown is for strategy of anticoagulant prophylaxis). A linkage term representing the complement of the effectiveness of withholding anticoagulant prophylaxis for reducing the risk of systemic bleeding was used to link the distal subtrees. This effectiveness term was calculated as follows: effectiveness of withholding anticoagulant prophylaxis = ((probability of systemic bleeding with LMWH) $-($ probability of systemic bleeding without LMWH))/(probability of systemic bleeding with LMWH). The circles represent chance nodes, and the triangles on the far right represent the outcome measure, expected utility. Numerical values under each branch are the baseline probabilities used at each chance node for the baseline case with administration of anticoagulant prophylaxis. Values to the right of each triangle are the final expected values (utility) for each state. Alive PE: survival after a pulmonary embolism; Alive w Systemic Bleed: survival after a systemic bleeding complication; CNS Bleed: progression of intracranial hemorrhage; Disabling: disabling neurological deficit; DVT: deep vein thrombosis; Non Disabling: non-disabling neurological deficit; No Sys Bleed: no systemic bleeding complication; PE: pulmonary embolism; Systemic Bleed: hemorrhagic complication not involving central nervous system.

DVT while withholding anticoagulation to avoid intracranial hemorrhagic progression. However, this strategy would have important cost considerations and did not yield an apparent benefit in our decision analysis or reduce DVT incidence in a recent large clinical trial in stroke patients [41].

A limitation of all decision analyses is that they rely on having accurate estimates of probabilities of outcomes following clinical choices, and such estimates often are lacking in the literature for the clinical scenario of interest. For example, a limitation of our decision analysis was the difficulty quantifying the incremental risk of intracranial hemorrhagic progression at 24 hours with anticoagulant prophylaxis. Our only estimate was derived from a single prospective study that lacked a control group, so we used a very wide confidence interval in sensitivity analysis. These analyses suggest that anticoagulant prophylaxis would still only become the most effective strategy if the true incremental risk of hemorrhagic progression were less than 5\% above baseline. Furthermore, the expected values associated with clinical choices in a decision analysis will depend on the utilities that are assigned to each clinical outcome, and different patients and clinicians may weigh such outcomes differently in the real world.

\section{Conclusions}

Our model showed no clear advantage to providing or withholding anticoagulant prophylaxis for DVT/PE prevention at 24 hours after traumatic brain injury associated with intracranial hemorrhage. In the context of such a toss-up, and given that the most disastrous event (other than death) encountered in this model is the development of a disabling neurological deficit, we would recommend against the use of routine anticoagulant prophylaxis at 24 hours for these patients. However, considering that both strategies were associated with nearly equivalent expected values, our model would suggest that it should 


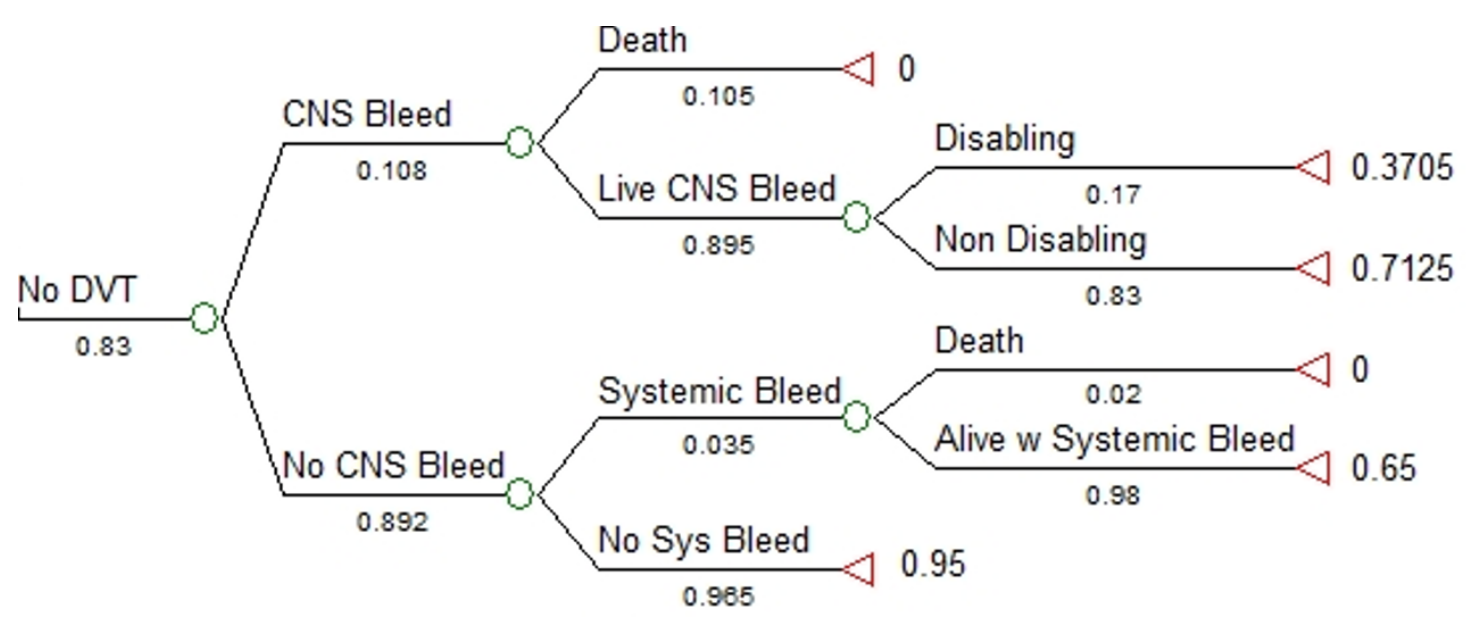

Figure 3 No deep vein thrombosis (DVT) subtree showing possible outcomes without development of DVT. The tree shown is for strategy of anticoagulant prophylaxis. A linkage term representing the complement of the effectiveness of withholding anticoagulant prophylaxis for reducing the risk of progression of $\mathrm{ICH}$ progression was used to link the main subtrees. This effectiveness term was calculated as follows: effectiveness of withholding anticoagulant prophylaxis $=($ (probability of $\mathrm{ICH}$ progression with LMWH) $-($ probability of ICH progression without LMWH))/(probability of ICH progression with $\mathrm{LMWH}$ ). The circles represent chance nodes, and the triangles on the far right represent the outcome measure, expected utility. Numerical values under each branch are the baseline probabilities used at each chance node for the baseline case and with administration of anticoagulant prophylaxis. Values to the right of each triangle are the final expected values (utility) for each state. Alive w Systemic Bleed: survival after a systemic bleeding complication; CNS Bleed: progression of intracranial hemorrhage; Disabling: disabling neurological deficit; DVT: deep vein thrombosis; Live CNS Bleed: survival after progression of intracranial hemorrhage; Non Disabling: non-disabling neurological deficit; No Sys Bleed: no systemic bleeding complication; Systemic Bleed: gastrointestinal bleeding.

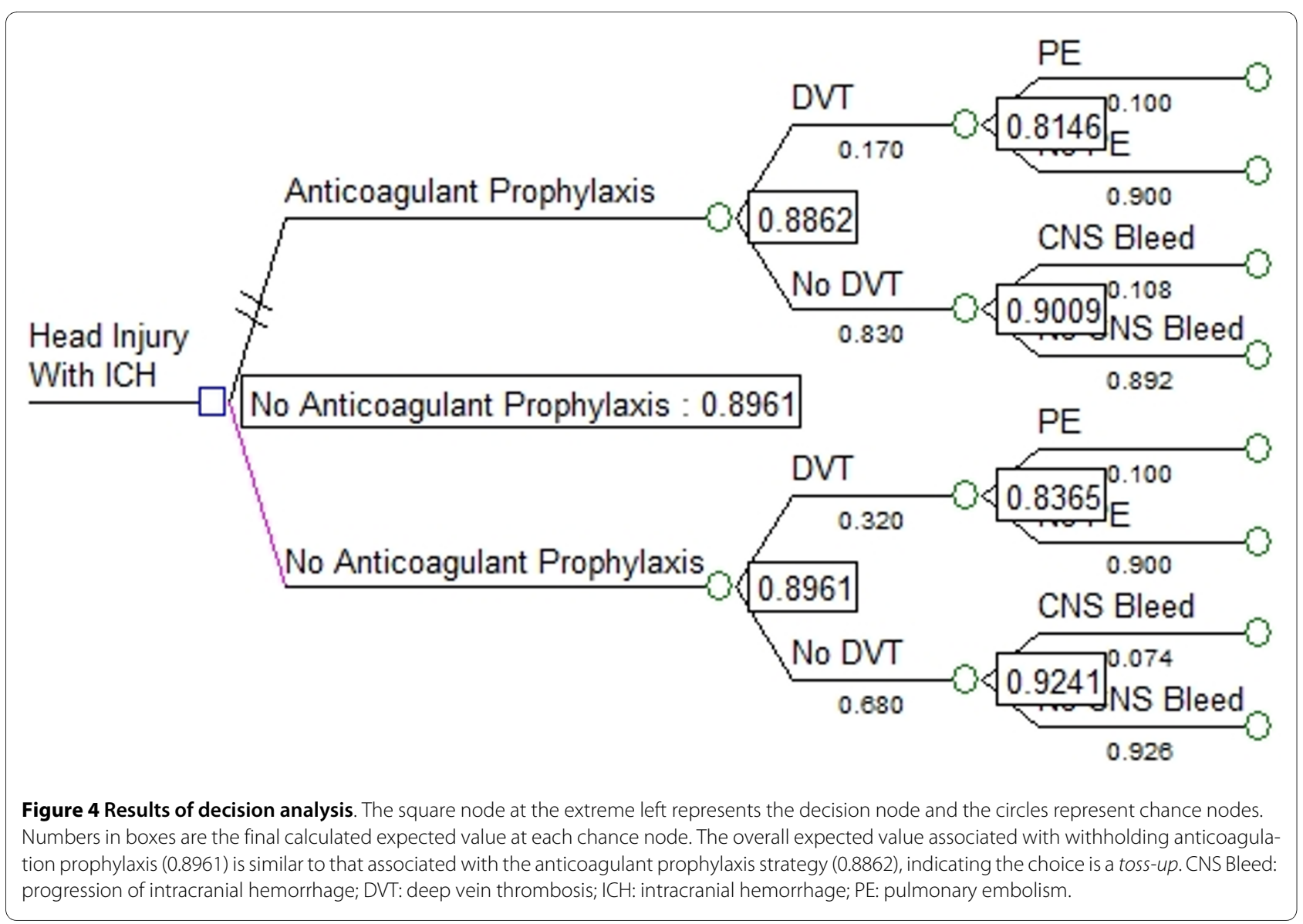




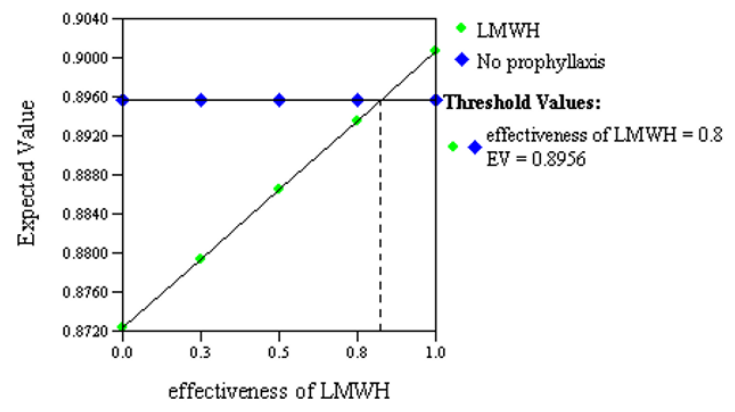

Figure 5 Sensitivity analysis on effectiveness of low molecular weight heparin at preventing deep venous thrombosis. One-way sensitivity analysis in which the relative effectiveness of low molecular weight heparin $(\mathrm{LMWH})$ at preventing deep vein thrombosis (DVT) is varied (small green diamonds). The two strategies (LMWH versus no prophylaxis) are seen to have equivalent expected values (utilities) at the point (threshold value) where the two lines intersect. This analysis suggests that providing LMWH at 24 hours after traumatic brain injury with intracranial hemorrhage would become the preferred strategy only if it was more than $80 \%$ effective at preventing DVT.

be ethical to conduct a randomized, controlled, clinical trial to evaluate the safety and efficacy of using anticoagulant prophylaxis in patients with traumatic brain injury and intracranial hemorrhage.

\section{Key messages}

- Patients with traumatic brain injury associated with intracranial hemorrhage are at high risk for developing venous thromboembolism

- Anticoagulation prophylaxis is proven to decrease the risk of venous thromboembolism in other patient

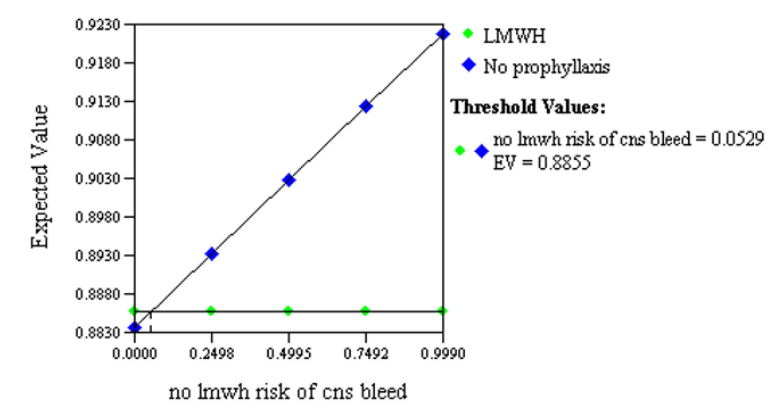

Figure 6 Sensitivity analysis on effectiveness of no anticoagulant prophylaxis at preventing progression of intracranial hemorrhage. One-way sensitivity analysis in which the relative effectiveness of withholding low molecular weight heparin (LMWH) to prevent progression of intracranial hemorrhage (CNS bleed) is varied (large blue diamonds). The two strategies (LMWH versus no prophylaxis) are seen to have equivalent expected values (utilities) at the point (threshold value) where the two lines intersect. This analysis suggests that $\mathrm{LMWH}$ would become the preferred strategy only if it increased the risk of intracranial hemorrhagic progression by no more than $5 \%$ above the baseline risk. groups, but may increase the risk of progression of intracranial hemorrhage

- The decision to provide anticoagulation prophylaxis to these patients therefore represents a trade-off that can be examined using decision analysis techniques - Our decision analysis model showed no clear advantage to providing or withholding anticoagulant prophylaxis for thromboembolic prophylaxis at 24 hours after traumatic brain injury associated with intracranial hemorrhage

- Randomized controlled trials of this study question are justifiable and needed to guide clinicians

\section{Abbreviations}

CNS: central nervous system; DVT: deep vein thrombosis; ICH: intracranial hemorrhage; ICU: intensive care unit; LMWH: low-molecular weight heparin; PE: pulmonary embolism; SYS: systemic bleeding.

\section{Competing interests}

The authors declare that they have no competing interests.

\section{Authors' contributions}

DCS, JRC, JTG and ASD conceived of and designed the manuscript. DCS, JRC, VA and DW were responsible for data acquisition. DCS, JRC, DW and ASD were responsible for analysis and interpretation. DCS, JRC, DW, VA, JTG and ASD drafted and revised the manuscript. All authors read and approved the final manuscript.

\section{Acknowledgements}

DCS is supported by a New Investigator Award from the Canadian Institutes for Health Research.

\section{Author Details}

1Department of Critical Care Medicine, Sunnybrook Health Sciences Centre, 2075 Bayview Avenue, Room D108, Toronto, ON M4N 3M5, Canada, 2Institute for Clinical Evaluative Sciences, 2075 Bayview Avenue, Room G157, Toronto, ON M4N 3M5, Canada, 3Interdepartmental Division of Critical Care Medicine and Department of Medicine, University of Toronto, 30 Bond Street, Toronto, ON M5B 1W8, Canada, ' ${ }^{2}$ epartment of Neurosurgery, Primary Children's Medical Centre, 100 N. Mario Capecchi Dr., Suite. 1475, Salt Lake City, Utah 84113, USA ${ }^{5}$ Department of Neurosurgery, University of Utah, 30 N. 1900 E, Salt Lake City, Utah 84132, USA, 6Faculty of Medicine, University of British Columbia, 17 - 2194 Health Sciences Mall, Vancouver, BC V6T 1Z3, Canada, ${ }^{7}$ Departments of Medicine and Critical Care, University Health Network, 11-1170 CSB, 585 University Ave, Toronto, ON M5G 2C4, Canada, ${ }^{8}$ Department of Medicine, Mount Sinai Hospital, 600 University Avenue, Suite 429, Toronto, ON M5G 1X5, Canada and ${ }^{9}$ Department of Health Policy, Management and Evaluation, University of Toronto, 155 College Street, Suite 425, Toronto, ON M5T 3M6, Canada

Received: 5 October 2009 Revised: 10 March 2010

Accepted: 20 April 2010 Published: 20 April 2010

\section{References}

1. Rutland-Brown W, Langlois JA, Thomas KE, Xi YL: Incidence of traumatic brain injury in the United States, 2003. J Head Trauma Rehabil 2006, 21:544-548.

2. Tabori U, Kornecki A, Sofer S, Constantini S, Paret G, Beck R, Sivan Y: Repeat computed tomographic scan within 24-48 hours of admission in children with moderate and severe head trauma. Crit Care Med 2000, 28:840-844.

3. Servadei F, Murray GD, Teasdale GM, Dearden M, lannotti F, Lapierre F, Maas AJ, Karimi A, Ohman J, Persson L, Stocchetti N, Trojanowski T, Unterberg A: Traumatic subarachnoid hemorrhage: demographic and clinical study of 750 patients from the European brain injury consortium survey of head injuries. Neurosurgery 2002, 50:261-267. 
4. Gudeman SK, Kishore PR, Miller JD, Girevendulis AK, Lipper MH, Becker DP: The genesis and significance of delayed traumatic intracerebral hematoma. Neurosurgery 1979, 5:309-313.

5. Oertel M, Kelly DF, McArthur D, Boscardin WJ, Glenn TC, Lee JH, Gravori T, Obukhov D, McBride DQ, Martin NA: Progressive hemorrhage after head trauma: predictors and consequences of the evolving injury. $J$ Neurosurg 2002, 96:109-116.

6. Stein SC, Spettell C, Young G, Ross SE: Delayed and progressive brain injury in closed-head trauma: radiological demonstration. Neurosurgery 1993, 32:25-30.

7. Knudson MM, Ikossi DG, Khaw L, Morabito D, Speetzen LS: Thromboembolism after trauma: an analysis of 1602 episodes from the American College of Surgeons National Trauma Data Bank. Ann Surg 2004, 240:490-496.

8. Geerts WH, Jay RM, Code KI, Chen E, Szalai JP, Saibil EA, Hamilton PA: A comparison of low-dose heparin with low-molecular-weight heparin as prophylaxis against venous thromboembolism after major trauma. NEngl J Med 1996, 335:701-707.

9. Joffe SN: Incidence of postoperative deep vein thrombosis in neurosurgical patients. J Neurosurg 1975, 42:201-203.

10. Valladares $J B$, Hankinson $\mathrm{J}$ : Incidence of lower extremity deep vein thrombosis in neurosurgical patients. Neurosurgery 1980, 6:138-141.

11. Zelikovski A, Zucker G, Eliashiv A, Reiss R, Shalit M: A new sequential pneumatic device for the prevention of deep vein thrombosis. $J$ Neurosurg 1981, 54:652-654.

12. Agnelli G, Piovella F, Buoncristiani P, Severi P, Pini M, D'Angelo A, Beltrametti C, Damiani M, Andrioli GC, Pugliese R, lorio A, Brambilla G: Enoxaparin plus compression stockings compared with compression stockings alone in the prevention of venous thromboembolism after elective neurosurgery. N Engl J Med 1998, 339:80-85.

13. Hirsh J, Guyatt G, Albers GW, Harrington R, Schunemann HJ, American College of Chest Physicians: Antithrombotic and thrombolytic therapy: American College of Chest Physicians Evidence-Based Clinical Practice Guidelines (8th Edition). Chest 2008, 133:110S-112S

14. Kurtoglu M, Yanar H, Bilsel Y, Guloglu R, Kizilirmak S, Buyukkurt D, Granit V: Venous thromboembolism prophylaxis after head and spinal trauma: intermittent pneumatic compression devices versus low molecular weight heparin. World J Surg 2004, 28:807-811.

15. Norwood SH, McAuley CE, Berne JD, Vallina VL, Kerns DB, Grahm TW, Short K, McLarty JW: Prospective evaluation of the safety of enoxaparin prophylaxis for venous thromboembolism in patients with intracranial hemorrhagic injuries. Arch Surg 2002, 137:696-701.

16. Cupitt JM, Cupitt JM: Prophylaxis against thromboembolism in patients with traumatic brain injury: a survey of UK practice. Anaesthesia 2001, 56:780-785

17. Scales DC, Riva-Cambrin J, Le TL, Pinto R, Cook DJ, Granton JT, Canadian Critical Care Trials Group: Prophylaxis against venous thromboembolism in neuro-intensive care patients: survey of Canadian practice. J Crit Care 2009, 24:176-184.

18. Denson K, Morgan D, Cunningham R, Nigliazzo A, Brackett D, Lane M, Smith B, Albrecht R: Incidence of venous thromboembolism in patients with traumatic brain injury. Am J Surg 2007, 193:380-383.

19. Nathens AB, McMurray MK, Cuschieri J, Durr EA, Moore EE, Bankey PE, Freeman B, Harbrecht BG, Johnson JL, Minei JP, McKinley BA, Moore FA, Shapiro MB, West MA, Tompkins RG, Maier RV: The practice of venous thromboembolism prophylaxis in the major trauma patient. J Trauma 2007, 62:557-562.

20. Last JM: A Dictionary of Epidemiology 4th edition. New York, New York: Oxford University Press; 2001.

21. Danish SF, Burnett MG, Ong JG, Sonnad SS, Maloney-Wilensky E, Stein SC: Prophylaxis for deep venous thrombosis in craniotomy patients: a decision analysis. Neurosurgery 2005, 56:1286-1292.

22. Geerts WH, Code Kl, Jay RM, Chen E, Szalai JP: A prospective study of venous thromboembolism after major trauma. NEngl J Med 1994, 331:1601-1606.

23. Cook DJ, Griffith LE, Walter SD, Guyatt GH, Meade MO, Heyland DK, Kirby A, Tryba M, Canadian Critical Care Trials Group: The attributable mortality and length of intensive care unit stay of clinically important gastrointestinal bleeding in critically ill patients. Crit Care 2001, 5:368-375.

24. Dickinson LD, Miller LD, Patel CP, Gupta SK: Enoxaparin increases the incidence of postoperative intracranial hemorrhage when initiated preoperatively for deep venous thrombosis prophylaxis in patients with brain tumors. Neurosurgery 1998, 43:1074-1081.

25. Macdonald RL, Amidei C, Baron J, Weir B, Brown F, Erickson RK, Hekmatpanah J, Frim D: Randomized, pilot study of intermittent pneumatic compression devices plus dalteparin versus intermittent pneumatic compression devices plus heparin for prevention of venous thromboembolism in patients undergoing craniotomy. Surgical Neurology 2003, 59:363-372.

26. Torrance GW: Utility approach to measuring health-related quality of life. J Chronic Dis 1987, 40:593-603.

27. Center for the Evaluation of Value and Risk in Health. The CostEffectiveness Analysis Registry [http://www.cearegistry.org]

28. Naglie G, Krahn MD, Naimark D, Redelmeier DA, Detsky AS: Primer on medical decision analysis: Part 3--Estimating probabilities and utilities. Med Decis Making 1997, 17:136-141.

29. Fryback DG, Dasbach EJ, Klein R, Klein BE, Dorn N, Peterson K, Martin PA: The Beaver Dam Health Outcomes Study: initial catalog of health-state quality factors. Med Decis Making 1993, 13:89-102.

30. Kaplan RM, Anderson JP: A general health policy model: update and applications. Health Serv Res 1988, 23:203-235.

31. Torrance GW: Measurement of health state utilities for economic appraisal. J Health Econ 1986, 5:1-30.

32. Brothers TE, Frank CE, Frank B, Robison JG, Elliott BM, Del Schutte H, Merrill $K D$, Friedman RJ: Is duplex venous surveillance worthwhile after arthroplasty? J Surg Res 1997, 67:72-78.

33. Kellett J, Clarke J, Kellett J, Clarke J: Comparison of "accelerated" tissue plasminogen activator with streptokinase for treatment of suspected myocardial infarction. (see comment). (Review) (145 refs). Medical Decision Making 1995, 15:297-310.

34. Lee TT, Solomon NA, Heidenreich PA, Oehlert J, Garber AM: Costeffectiveness of screening for carotid stenosis in asymptomatic persons[see comment]. Annals of Internal Medicine 1997, 126:337-346.

35. Sarasin FP, Eckman MH: Management and prevention of thromboembolic events in patients with cancer-related hypercoagulable states: a risky business. J Gen Intern Med 1993, 8:476-486.

36. Kerridge RK, Glasziou PP, Hillman KM: The use of "quality-adjusted life years" (QALYs) to evaluate treatment in intensive care. Anaesth Intensive Care 1995, 23:322-331

37. van Swieten JC, Koudstaal PJ, Visser MC, Schouten HJ, van Gijn J. Interobserver agreement for the assessment of handicap in stroke patients. Stroke 1988, 19:604-607.

38. Detsky AS, Naglie G, Krahn MD, Redelmeier DA, Naimark D: Primer on medical decision analysis: Part 2: Building a tree. Med Decis Making 1997, 17:126-135.

39. Krahn MD, Naglie G, Naimark D, Redelmeier DA, Detsky AS: Primer on medical decision analysis: Part 4: Analyzing the model and interpreting the results. Med Decis Making 1997, 17:142-151.

40. Collen JF, Jackson JL, Shorr AF, Moores LK: Prevention of venous thromboembolism in neurosurgery: a metaanalysis. Chest 2008, 134:237-249.

41. Dennis M, Sandercock PA, Reid J, Graham C, Murray G, Venables G, Rudd A, Bowler $\mathrm{G}$ : Effectiveness of thigh-length graduated compression stockings to reduce the risk of deep vein thrombosis after stroke (CLOTS trial 1): a multicentre, randomised controlled trial. Lancet 2009, 373:1958-1965.

42. Ginsberg JS: Management of venous thromboembolism. N Engl J Med 1996, 335:1816-1828.

43. Monreal M, Ruiz J, Olazabal A, Arias A, Roca J: Deep venous thrombosis and the risk of pulmonary embolism. A systematic study. Chest 1992, 102:677-681.

44. McLeod RS, Geerts WH, Sniderman KW, Greenwood C, Gregoire RC, Taylor BM, Silverman RE, Atkinson KG, Burnstein M, Marshall JC, Burul CJ, Anderson DR, Ross T, Wilson SR, Barton P, other investigators of the Canadian Colorectal Surgery DVT Prophylaxis Trial: Subcutaneous heparin versus low-molecular-weight heparin as thromboprophylaxis in patients undergoing colorectal surgery: results of the canadian colorectal DVT prophylaxis trial: a randomized, double-blind trial. Ann Surg 2001, 233:438-444

45. Rogers FB, Shackford SR, Wilson J, Ricci MA, Morris CS: Prophylactic vena cava filter insertion in severely injured trauma patients: indications and preliminary results. J Trauma 1993, 35:637-641. 
46. Goldhaber SZ, Visani L, De Rosa M: Acute pulmonary embolism: clinical outcomes in the International Cooperative Pulmonary Embolism Registry (ICOPER). Lancet 1999, 353:1386-1389.

47. Collins R, Scrimgeour A, Yusuf S, Peto R: Reduction in fatal pulmonary embolism and venous thrombosis by perioperative administration of subcutaneous heparin. Overview of results of randomized trials in general, orthopedic, and urologic surgery. N Engl J Med 1988, 318:1162-1173

48. Patel NY, Hoyt DB, Nakaji P, Marshall L, Holbrook T, Coimbra R, Winchell RJ, Mikulaschek AW: Traumatic brain injury: patterns of failure of nonoperative management. J Trauma 2000, 48:367-374

49. Caroli M, Locatelli M, Campanella R, Balbi S, Martinelli F, Arienta C: Multiple intracranial lesions in head injury: clinical considerations, prognostic factors, management, and results in 95 patients. Surg Neurol 2001, 56:82-88.

50. Radberg JA, Olsson JE, Radberg CT: Prognostic parameters in spontaneous intracerebral hematomas with special reference to anticoagulant treatment. Stroke 1991, 22:571-576.

51. Swash M, Oxbury J: Clinical Neurology 3rd edition. New York: ChurchillLivingstone; 1991.

52. Daverat P, Castel JP, Dartigues JF, Orgogozo JM: Death and functional outcome after spontaneous intracerebral hemorrhage. A prospective study of 166 cases using multivariate analysis. Stroke 1991, 22:1-6.

53. Siddique MS, Gregson BA, Fernandes HM, Barnes J, Treadwell L, Wooldridge TD, Mendelow AD: Comparative study of traumatic and spontaneous intracerebral hemorrhage. J Neurosurg 2002, 96:86-89.

54. Lipper MH, Kishore PR, Girevendulis AK, Miller JD, Becker DP: Delayed intracranial hematoma in patients with severe head injury. Radiology 1979, 133:645-649.

55. Shorr AF, Ramage AS: Enoxaparin for thromboprophylaxis after major trauma: potential cost implications. Crit Care Med 2001, 29:1659-1665.

56. Gage BF, Cardinalli AB, Albers GW, Owens DK: Cost-effectiveness of warfarin and aspirin for prophylaxis of stroke in patients with nonvalvular atrial fibrillation[see comment]. JAMA 1995, 274:1839-1845

57. Tengs TO, Yu M, Luistro E: Health-related quality of life after stroke a comprehensive review. Stroke 2001, 32:964-972.

doi: $10.1186 / \mathrm{cc} 8980$

Cite this article as: Scales et al., Prophylactic anticoagulation to prevent venous thromboembolism in traumatic intracranial hemorrhage: a decision analysis Critical Care 2010, 14:R72

Submit your next manuscript to BioMed Centra and take full advantage of:

- Convenient online submission

- Thorough peer review

- No space constraints or color figure charges

- Immediate publication on acceptance

- Inclusion in PubMed, CAS, Scopus and Google Scholar

- Research which is freely available for redistribution

Submit your manuscript at www.biomedcentral.com/submit
C) Biomed Central 